programa é paquidérmico, estamos nisso desde 1994. Não há projeto consistente para formação dos 60 mil médicos e enfermeiros de família de que necessitaríamos. Há espasmos pedagógicos com nomes pomposos, no entanto, nenhum governo apresentou estratégia efetiva e parcerias consistentes para enfrentar esse desafio educacional. Isto sem comentar a indigência dos modos de contratação e de gestão de pessoal. Hoje, já há evidências indicando que não há como os municípios isolados resolverem a política de pessoal para o SUS. Necessitam do concurso efetivo, financeiro, legal e organizacional dos Estados e da União. Não há evidências de que o Ministério da Saúde esteja disposto a assumir a articulação dessa multiplicidade de experiências e de entidades federadas para construir um sistema - rede interdependente, apesar da autonomia dos municípios - que combine singularidade local com diretrizes que assegurem unidade ao SUS.

Por tudo isso, é que saúdo o artigo de Conill com alvíssaras. Viva! Encontramos alguém disposto a pensar de maneira crítica e construtiva e ampla e cuidando, ao mesmo tempo, em preservar os valores e diretrizes que fazem do SUS uma esperança de que a vida real não seja somente competição e violência e... Salve! Saravá!

1. Pan American Health Organization. Renewing primary health care in the Americas. A position paper of the Pan American Health Organization/WHO. Washington DC: Pan American Health Organization/World Health Organization; 2005.

2. Mendes-Gonçalves RB. Tecnologia e organização social das práticas de saúde. São Paulo: Editora Hucitec; 1994.

Luis Fernando Rolim Sampaio

Secretaria de Atenção à Saúde, Ministério da Saúde, Brasília, Brasil. luis.fernando@saude.gov.br
A Atenção Primária à Saúde vem recebendo, atualmente, especial atenção dos governos e da academia em todo o mundo. A Organização Mundial da Saúde (OMS) dedica o relatório mundial de 2008 ao tema, e sua Diretora Geral, Magareth Chan, apontou, como um dos três pontos prioritários de sua gestão, a Atenção Primária à Saúde, alegando que, em sua campanha pela direção da instituição, visitou diversos países e ministros da saúde em todos os continentes, e a Atenção Primária à Saúde foi um ponto destacado como agregador na luta pela saúde dos povos. A Organização Pan-Americana da Saúde (OPAS) contribuiu com a publicação do documento Renewing Primary Health Care in the Americas. A Position
Paper of the Pan American Health Organization/ $W H O{ }^{1}$. Isso reforça sobremaneira a importância de o Brasil apresentar sua experiência e seu desenvolvimento teórico nesse campo, e a contribuição que nos traz a professora Conill é extremamente relevante.

Minha contribuição ao debate vem do campo da gestão, no qual atuo e pude acompanhar a implantação do Sistema Único de Saúde (SUS) e da Saúde da Família, que, esse ano, celebra seus 15 anos. Buscarei, assim, dialogar com a autora na discussão do processo incremental de mudança da Atenção Primária à Saúde em curso no Brasil.

Como bem destaca a autora, estamos em um momento de retorno à ênfase na Atenção Primária à Saúde, mas, no momento precedente, os entendimentos restritivos derivados da polissemia do termo questionam a contribuição da Atenção Primária à Saúde no Brasil. A noção de cuidados primários de saúde, com um caráter de programa de medicina simplificada para os pobres de áreas urbanas e rurais, em vez de uma estratégia de reorientação do sistema de serviços de saúde, afastou o tema das proposições elaboradas na VIII Conferência Nacional de Saúde 2 . Testa afirmava aquela época que não é possível considerar a atenção primária de saúde como um conceito totalizante, com a mesma validade em qualquer país e circunstância, alertando para o risco da simplificação e da atenção primitiva de saúde 3 . Considerando a Atenção Primária à Saúde um conceito subdesenvolvido e com necessidade de aprimoramento, Schraiber \& Mendes-Gonçalves apontam que "a atenção primária tem sido associada a uma assistência de baixo custo, pois parece tratar-se de um serviço simples e quase sempre com poucos equipamentos" 4 (p. 34).

Assim, a emergência do Programa Saúde da Família (PSF) se deu sob críticas de setores acadêmicos, à época, reforçadas pelo contexto internacional, devido à publicação do documento Relatório Sobre o Desenvolvimento Mundial 1993. Investindo em Saúde pelo Banco Mundial 5. Várias leituras foram feitas naquele momento, entre elas, do renascimento de uma proposta entendida como já superada, baseada em experiências como a da Medicina Geral e Comunitária ou de um programa vertical e focalizado ${ }^{6,7}$ ou a idéia de uma medicina de pobre para os miseráveis ${ }^{8}$.

Efetivamente, a discussão acadêmica brasileira, na década de 90, trouxe pouca contribuição ao desenvolvimento teórico da Atenção Primária à Saúde. Isso é compatível com o pequeno volume de literatura nacional disponível sobre o tema no período. Esse cenário sofreu uma mudança gradativa, provocada, em especial, pela operacionalização do PSF. Consultando publicações nas bases LILACS, MEDLINE e SciELO dos 
últimos 15 anos, observamos crescimento significativo de artigos sobre Saúde da Família/Family Health delimitado no Brasil. De 1993 a 1997, são citadas 325 publicações aumentando para 1.244 no período de 1998-2002 e chegando a 2.205 de 2003 a 2007.

No campo da gestão, por outro lado, muitos movimentos foram feitos no sentido do fortalecimento da Atenção Primária à Saúde. A criação do Departamento de Atenção Básica (utilizarei o termo Atenção Básica como sinônimo de Atenção Primária à Saúde, conservando o termo atenção básica somente na nominação da estrutura e regulamentações do Ministério da Saúde) no Ministério da Saúde institucionalizou uma prioridade política. Esse processo se refletiu nos estados e municípios que reformularam seus organogramas, potencializando o papel articulador e estratégico da Atenção Primária à Saúde, passando a congregar várias iniciativas que compõem o seu escopo. Em dez anos, as coordenações de agentes comunitários e de saúde da família, que apareciam como áreas ou programas, sem significado político-estratégico, modificaram seu status, e, atualmente, em 20 das 27 Secretarias de Estado de Saúde, a Atenção Primária à Saúde encontrase no primeiro ou segundo escalões de governo.

Nesse contexto, a proposta de institucionalização da avaliação na atenção básica, a que se refere a autora, é parte desse movimento incremental de construção da Atenção Primária à Saúde. A preocupação com a avaliação, por parte da direção do Departamento de Atenção Básica, já havia estimulado a criação do Sistema de Informação da Atenção Básica (SIAB), proposto como ferramenta para apoiar os gestores e as equipes, bem como a criação do Pacto de Indicadores da Atenção Básica, ainda na década de 90. O PROESF - Projeto de Expansão e Consolidação do Saúde da Família, na década seguinte, viabilizou recursos financeiros para ampliar esse movimento, permitindo que várias instituições acadêmicas, anteriormente apartadas do tema e que não tinham a Atenção Primária à Saúde e a saúde da família em sua agenda de prioridades, pudessem iniciar movimentos de aproximação com a mesma. Ainda assim, o tema ainda não consta da agenda nacional de prioridades de pesquisa em saúde e, tampouco, vem constando nos eixos temáticos dos congressos do campo da Saúde Coletiva.

Um marco para o avanço da Atenção Primária à Saúde no Brasil foi a publicação da Política Nacional de Atenção Básica - PNAB 9. A discussão de uma revisão normativa da Atenção Básica e da Saúde da Família se arrastou por vários anos pelo receio que a mesma pudesse comprometer os princípios fundamentais da estratégia em cur- so. A PNAB, publicada em 2006, levou a revogação de 27 Portarias que, desde 1997, promoviam adequações normativas na operacionalização da atenção básica. A partir dessa norma, tomou-se a decisão política de chamar a saúde da família de uma estratégia nacional e não mais um programa, buscando dar uma dimensão ampliada à Saúde da Família.

Como destacou a autora, uma confluência de fatores parece explicar a emergência do PSF e do Programa de Agentes Comunitários de Saúde (PACS). Adiciono e reforço algumas questões que considero relevantes na expansão e consolidação da saúde da família.

A primeira delas é o compromisso de prefeitos, e outros atores políticos, independente da coloração partidária, os quais têm, como um dos motivadores principais, o retorno político eleitoral. As pesquisas de opinião que avaliam a expansão da Saúde da Família e seu reflexo na avaliação da gestão municipal existem e demonstram que a boa avaliação do programa feita pela população se reflete positivamente na avaliação dos governos.

O compromisso político refletiu-se na garantia de financiamento federal perene, implantado, a partir de 1998, com a introdução do Piso de Atenção Básica. Mesmo com o Piso de Atenção Básica, os municípios são os responsáveis pela maior parte do financiamento. A adesão dos estados ao financiamento da Atenção Primária à Saúde e da Saúde da Família é tardia, mas incentivos específicos já estão implantados em mais da metade dessas unidades federadas.

A normatização de infra-estrutura para as unidades de saúde da família, com uma equipe mínima nacional e com ações e atividades propostas, foi outra importante questão no desenvolvimento da Saúde da Família. Apesar das críticas feitas à impossibilidade de uma norma nacional atender as diferentes realidades do país e do engessamento operacional a que são submetidos estados e municípios diante das normativas ministeriais, no caso específico da saúde da família, a parametrização apontada ajudou a viabilizar o cunho nacional da estratégia.

A criação e manutenção de um corpo técnico tanto na esfera federal como nas outras esferas de governo, capitaneado pelo Ministério da Saúde, que foi acumulando conhecimento e poder político e se consolidando como um novo espaço na construção do SUS, é outro fator do sucesso da estratégia. Em estudos de casos de experiências exitosas no Brasil, a parceria do Ministério da Saúde com lideranças de municípios foi considerada um dos fatores cruciais para o sucesso das mesmas. Por outro lado, é destacada a ausência das universidades nessas experiências 10 . 
Nesse sentido, é importante que o Brasil avance na construção do campo de conhecimento e de prática da Atenção Primária à Saúde, ainda pouco explorado pela academia brasileira, deixando, ao largo, preconceitos e idéias pré-formatadas, como a dos pacotes assistenciais dos anos 1980 e 1990.

No encerramento do debate, aponto o desafio da avaliação nas duas vertentes citadas pela autora: da profusão e da comunicação. A profusão poderia ser minimizada com uma maior aproximação e participação efetiva dos serviços e gestores na elaboração das questões e desenhos dos estudos. Isso ajudaria na comunicação dos resultados e na realização de intervenções e mudanças, pois a integração prévia dos grupos acadêmicos e dos serviços permite uma sensibilização para uma posterior intervenção.

Destacaria, ainda, que os avanços conquistados pelo Brasil na Atenção Primária à Saúde, nos últimos anos, são substanciais, e que o fato de o Brasil estar hoje numa posição de liderança do tema no cenário mundial se deve, essencialmente, à decisão e ao compromisso político dos governos e da sociedade de investir na superação do desafio de construção de uma estratégia nacional para um país continental.

1. Pan American Health Organization. Renewing primary health care in the Americas. A position paper of the Pan American Health Organization/WHO. Washington DC: Pan American Health Organization/World Health Organization; 2005.

2. Paim JS. Descentralização das ações e serviços de saúde no Brasil e a renovação da proposta "Saúde para Todos". Rio de Janeiro: Instituto de Medicina Social, Universidade do Estado do Rio de Janeiro; 1998. (Série Estudos em Saúde Coletiva, 175).

3. Testa M. Atenção primária (ou primitiva) de saúde. In: Testa M, organizador. Pensar em saúde. Porto Alegre: Editora Artes Médicas; 1992. p. 160-74.

4. Schraiber LB, Mendes-Gonçalves RB. Necessidades de saúde e atenção primária. In: Schraiber LB, Nemes MIB, Mendes-Gonçalves RB, organizadores. Saúde do adulto, programas e ações na unidade básica. São Paulo: Editora Hucitec; 1996. p. 29-47.

5. Banco Mundial. Relatório sobre o desenvolvimento mundial 1993. Investindo em saúde. Rio de Janeiro: Fundação Getúlio Vargas; 1993.

6. Misoczky MC. A medicina de família, os ouvidos do príncipe e os compromissos do SUS. Saúde Debate, 1994; 42:40-4.

7. Franco T, Merhy EE. Programa de Saúde da Família: contradições e novos desafios. In: Anais do VI Congresso Paulista de Saúde Pública. v. 2. São Paulo: Associação Paulista de Saúde Pública; 1999. p. 145-54.

8. Campos FE, Belisário SAA. O Programa de Saúde da Família e os desafios para a formação profissional e a educação continuada. Interface Comun Saúde Educ 2001; 5:133-42.
9. Departamento de Atenção Básica, Secretaria de Atenção à Saúde, Ministério da Saúde. Política Nacional de Atenção Básica. Brasília: Ministério da Saúde; 2006. (Série Pactos pela Saúde, 4).

10. Goulart F. Saúde da família: boas práticas e círculos virtuosos. Uberlândia: Editora da Universidade Federal de Uberlândia; 2007.

\section{Ligia Atenção Primária à Saúde seletiva ou Giovanella abrangente?}

Escola Nacional de Saúde Pública Sergio Arouca, Fundação Oswaldo Cruz, Rio de Janeiro, Brasil. giovanel@ensp. fiocruz.br
O debate internacional e nacional sobre estratégias de Atenção Primária à Saúde foi intensificado na última década, e medidas para fortalecê-la fazem parte das reformas de saúde em diversos países europeus e latino-americanos, sendo assim muito bem-vindo o ensaio de Eleonor Minho Conill.

A partir de revisão de literatura internacional sobre casos específicos e selecionada análise de estudos recentes sobre a atenção básica/atenção primária no Brasil, a autora discute a trajetória da atenção primária enquanto política de reforma setorial. Descritos de forma clara e sintética, destacando os elementos centrais para a análise, os casos internacionais estudados, Canadá e Reino Unido, exemplificam experiências de países nos quais a atenção primária foi foco de um processo reiterado de reformas e permitem sinalizar as trajetórias da Atenção Primária à Saúde em países de industrialização avançada. A autora aponta, com fundamento, uma tendência nas reformas em saúde mais recentes de fortalecimento da atenção primária e de integração da rede assistencial. Para o Brasil, sua análise destaca resultados, condicionantes e desafios para a política de Atenção Primária à Saúde.

Atenção primária em saúde é termo que envolve distintas interpretações, como apontado pela autora que identifica duas concepções predominantes: cuidados ambulatoriais na porta de entrada e como política de reorganização do modelo assistencial de forma seletiva ou ampliada. Todavia, as concepções seletiva e ampliada de atenção primária subentendem questões teóricas, ideológicas e práticas muito distintas com conseqüências diferenciadas quanto às política implementadas e à garantia do direito universal à saúde, e valeria distingui-las apontando três interpretações principais. Uma primeira, mais comum em países europeus, como discutido pe- 